\title{
The assessment and treatment of panic disorder in general practice
}

\section{N Koen MBChB \& DJ Stein PhD, FRCPC}

To cite this article: N Koen MBChB \& DJ Stein PhD, FRCPC (2012) The assessment and treatment of panic disorder in general practice, South African Family Practice, 54:6, 472-477, DOI: $10.1080 / 20786204.2012 .10874277$

To link to this article: http://dx.doi.org/10.1080/20786204.2012.10874277
а (c) 2012 SAAFP. Published by Medpharm.

曲 Published online: 15 Aug 2014.

Submit your article to this journal $\pi$

山 Article views: 92

$Q^{\mathbf{2}}$

View related articles $\sqsubset$ 


\title{
The assessment and treatment of panic disorder in general practice
}

\author{
Koen N, MBChB, Fellow in Psychopharmacology \\ Stein DJ, FRCPC, PhD, Professor and Head \\ Department of Psychiatry and Mental Health, University of Cape Town \\ Correspondence to: Nastassja Koen, e-mail: nastassja.koen@gmail.com \\ Keywords: panic disorders, assessment, treatment
}

\begin{abstract}
Panic disorder $(\mathrm{PD})$ is an anxiety disorder that affects many South Africans. If undiagnosed or mismanaged, this condition may impact profoundly on an individual's functioning and quality of life. At the primary level, the assessment of panic attacks requires consideration of a number of differential diagnoses. General practitioners also play an invaluable role in the acute and long-term care and appropriate referral of individuals with PD. This article provides an overview of PD in general practice and includes a guideline for case identification and therapeutic options.
\end{abstract}

(c) Medpharm

S Afr Fam Pract 2012;54(6):472-477

\section{Introduction}

In the recent South African Stress and Health Study (SASH), the first large-scale, nationally conducted population-based survey of mental disorders, the population prevalence of panic disorder $(\mathrm{PD})$ was estimated to be approximately $1.2 \% .{ }^{1}$ Although this was somewhat lower than international estimates, ${ }^{2,3} \mathrm{PD}$ was also found to be the anxiety disorder that was most commonly associated with severe symptoms and functional impairment. Adults who were older than 35 years bore the largest burden of disease. Females were at greater risk than males.

$\mathrm{PD}$ is a chronic condition that often follows an intermittent course. Over time, there are relapses and remissions. ${ }^{4-6}$ It is characterised by the recurrence of unexpected panic attacks, which are then often followed by anticipatory concern. Typically, the age of onset of this disorder is late adolescence to the mid-30s. ${ }^{7}$

\section{Pathogenesis of panic disorder}

The pathophysiology of PD is multifactorial. There is strong evidence of familial aggregation. First-degree relatives are more liable to develop PD than the general population. . $^{8-11}$ The majority of this familial risk is thought to be conferred by genetic factors. Twin studies have strengthened the case for genes, rather than for common family environments, in predicting $\mathrm{PD}$, as evidenced by the higher concordance in monozygotic twins vs. dizygotic twins. ${ }^{12,13}$ According to the "equal environments assumption", ${ }^{8}$ monozygotic intrapair correlation is more strongly attributable to genetic resemblance, rather than to environmental similarities. That being said, individual specific environmental conditioning, such as early parental separation or childhood trauma, may also contribute to varying liability to PD.,14-17

It has also been suggested that neurobiological abnormalities in regions such as the medial prefrontal cortex, brainstem and limbic system (including the temporal lobe, amygdala and hippocampus) mediate PD. ${ }^{14,18-20}$ This is in line with the current understanding of the neurocircuitry of fear, in which the amygdala facilitates the processing of sensory input from the cortex to efferent target organs. ${ }^{14}$ The role of neurochemical and molecular derangements in these pathways is also increasingly understood. The serotonergic, ${ }^{21}$ noradrenergic ${ }^{22}$ and neuropeptidergic ${ }^{23,24}$ systems have been found to be particularly important in the mediation of $\mathrm{PD}$ and have been the targets of major treatment strategies.

Single-gene polymorphisms in these classic neurotransmitter systems have also been the subject of recent work. For example, variations in the monoamine oxidase $A,{ }^{25}$ catechol-O-methyltransferase ${ }^{26}$ and cholecystokinin $B$ recepto $^{23}$ genes have shown associations with PD. However, these findings have not been consistently replicated and no specific susceptibility loci have been established. ${ }^{27-29}$ Thus, a genome-wide association approach is increasingly being used to delineate such loci. ${ }^{30,31}$ Additional, genome-wide association studies in larger population samples, as well as gene-environment interaction studies, are needed to confirm preliminary results. 


\section{Diagnosing and assessing panic disorder in general practice}

In many cases, the diagnosis of PD is likely to be the responsibility of the general practitioner. Access to specialist psychiatric care is limited for most South Africans, so primary care practitioners should be equipped to identify and manage such cases. ${ }^{32}$ According to the proposed Diagnostic and Statistical Manual of Mental Disorders, 5th edition (DSM-V) diagnostic criteria ${ }^{6}$ (Table I), the hallmark clinical feature of PD is the recurrent, unexpected panic attack. These attacks are characterised by a sudden surge of intense fear or discomfort, the severity of which usually peaks within minutes. ${ }^{33}$ Symptoms of a panic attack include cardiovascular, e.g. chest pain and palpitations; respiratory, e.g. shortness of breath and choking sensations; gastrointestinal, e.g. nausea; neurological, e.g. dizziness and paraesthesias; autonomic, e.g. sweating, trembling, chills and heat sensations; and psychiatric features, e.g. derealisation, depersonalisation, fear of dying, losing control and going "mad". For a definitive diagnosis, four or more of these symptoms should be present. ${ }^{33}$ These attacks are then followed by persistent anxiety about future attacks, with resultant behaviour changes, e.g. avoidance of settings or situations thought to be associated with such attacks (Table I). While it has been suggested that the heterogeneity of PD warrants categorisation into distinct subtypes, e.g. respiratory, nocturnal, non-fearful, cognitive and vestibular, further work is needed before this subtyping is widely implemented in clinical practice. ${ }^{34}$

The clinical presentation of PD is highly heterogenous. In fact, individuals are more likely to complain of physical symptoms which they attribute to general medical conditions, rather than correctly identifying a panic attack. ${ }^{35}$ Respiratory illnesses are of particular interest in persons with PD, and their association has often been explained by Klein's "false suffocation alarm". ${ }^{36}$ This theory posits that locus coeruleus hyperactivity in individuals with PD leads to a hypersensitivity to subtle increases in arterial carbon dioxide. These increases are misperceived as a state of asphyxia and result in inappropriate hyperventilation. As obstructive pulmonary disease is often also associated with intermittent hypercapnia, these individuals are at increased risk of hyperventilation and panic. ${ }^{7,37}$ This may explain the overlapping symptomatology and high rate of co-morbidity between PD and asthma/chronic obstructive pulmonary disease. ${ }^{38-40}$

Once a panic attack has been correctly diagnosed, it is important to ascertain whether this feature is a component of PD, or some other anxiety or non-anxiety disorder. ${ }^{33}$ While a necessary feature of $\mathrm{PD}$, panic attacks alone are not sufficient to diagnose this disorder, as they may manifest in a variety of clinical scenarios. For example, panic attacks that are limited to particular situations are more likely to be a symptom of social anxiety disorder (if these occur when individuals are forced into social interactions), or of a specific phobia (if these occur when individuals are exposed to phobic stimuli, e.g. heights or receiving an injection). ${ }^{6,7}$ Similarly, if the attacks occur only when the person is reminded of a recent trauma, a diagnosis of posttraumatic stress disorder is most likely. If the symptoms are associated with obsessive thoughts and occur in conjunction with repetitive, time-consuming compulsive behaviours, the person should be assessed for obsessivecompulsive disorder. ${ }^{6}$ By contrast, panic attacks that are not bound to the situation, and which instead occur in a range of varied and unexpected settings, may signify a $P D$ diagnosis.

The frequency and intensity of attacks should also be elicited in order to determine the degree of functional impairment that is experienced by the individual. Typically, individuals with PD exhibit maladaptive behaviour changes, which in their most severe form, may result in agoraphobic avoidance of a variety of commonplace situations, e.g. crowds, open spaces and public transportation..$^{41}$

Persons with PD are also more at risk of suffering from a range of co-morbidities. ${ }^{2}$ For example, PD and major depression have been found to be significantly interrelated. ${ }^{2}$ From a clinical perspective, this co-occurrence has

Table I: Proposed DSM-V diagnostic criteria for panic disorder

A. Recurrent, unexpected panic attacks.

B. At least one of the attacks has been followed by one month (or more) of one or both of the following:

1. Persistent concern or worry about additional panic attacks or their consequences, e.g. losing control, having a heart attack or "going crazy".

2. Significant maladaptive change in behaviour that relate to the attacks, e.g. behaviours designed to avoid having panic attacks, such as avoidance of exercise or unfamiliar situations.

C. The disturbance is not attributable to the direct physiological effects of a substance, e.g. a drug of abuse, a medication or another medical condition, e.g. hyperthyroidism and cardiopulmonary disorders.

D. The disturbance is not better accounted for by another mental disorder, e.g. the panic attacks do not occur only in response to feared social situations (in social anxiety disorder), circumscribed phobic objects or situations (in specific phobia), obsessions (in obsessive-compulsive disorder), reminders of traumatic events (in post-traumatic stress disorder), or separation from attachment figures (in separation anxiety disorder). 
important prognostic implications as individuals with $\mathrm{PD}$ and co-morbid major depression often experience increased symptom severity (with augmented suicide risk), a higher degree of functional impairment and poorer longterm treatment response. ${ }^{7,42}$

Overall, individuals with PD tend to be high utilisers of primary healthcare services. ${ }^{43}$ This may be because of hypersensitivity to severe symptoms or misattribution of these symptoms to acute medical illness. ${ }^{7,44}$ Thus, misdiagnosis or inappropriate management of PD at the primary level can have far-reaching consequences, not only for the individual and his or her family, but also for the healthcare system as a whole.

\section{Guidelines for management}

\section{Acute treatment}

In the acute setting, a number of pharmacological or psychological treatments have proven effective in persons with PD. Ultimately, management should be individualised and based on personal preference, co-morbidities, previous treatment response and tolerability. ${ }^{45-47}$ First-line pharmacological agents include the selective serotonin reuptake inhibitors (SSRIs) and serotonin-noradrenaline reuptake inhibitors (SNRIs), both of which also have antidepressant efficacy. While fluoxetine, ${ }^{48,49}$ sertraline, ${ }^{50,51}$ paroxetine, ${ }^{52}$ and the SNRI, venlafaxine, ${ }^{53,54}$ have been most rigorously investigated, there seems to be little difference in efficacy within and between these drug classes..$^{55}$

As a general rule, the chosen pharmacotherapeutic agent should be started at very low dose. Individuals with PD have been found to be particularly sensitive to the side-effects of drug therapy and may even mistake adverse effects such as dizziness, tremor and tachycardia for the physical symptoms of a panic attack. ${ }^{56}$ Thus, to encourage treatment adherence, it is important to prepare patients for the occurrence of side-effects, e.g. gastrointestinal disturbances, anticholinergic effects and sexual disturbance, which are usually common during treatment initiation. Although some symptom improvement may be evident within a week of starting treatment, an acute trial should be undertaken for approximately six to eight weeks. ${ }^{46,57}$ During this time, drug dosage should be increased incrementally, e.g. one- to twoweekly, until the therapeutic range is reached. ${ }^{46}$

In the short-term, adjunctive benzodiazepines, e.g. clonazepam treatment, may also be helpful in hastening treatment response, particularly in the case of severe symptoms. ${ }^{58,59}$ However, given their unfavourable sideeffect profile and associated problems of dependence and rebound anxiety, ${ }^{60,61}$ benzodiazepines should not be used as first-line monotherapy for persons with PD. ${ }^{45-47}$
Of the nonpharmacological treatment options, cognitivebehavioural therapy (CBT) has consistenly been found to be the most effective. ${ }^{62,63}$ Generally, key components include psycho-education, cognitive strategies and exposure or desensitisation therapy. ${ }^{46,64}$ At the primary level, general practitioners may certainly implement simple psychotherapeutic interventions, such as providing information about PD to individuals and their families and encouraging exposure to, rather than avoidance of, feared stimuli. There is surprisingly little evidence in favour of the combined use of pharmaco- and psychotherapeutic interventions in the treatment of $\mathrm{PD}, 45$ although from a theoretical perspective, it may be useful to adopt a sequential approach, as medication has a faster onset and $\mathrm{CBT}$ facilitates a more sustained response.

\section{Long-term treatment}

When the individual has demonstrated a satisfactory response to acute treatment, pharmacotherapy should be continued for at least 8-12 months. ${ }^{46,65}$ Once the decision has been made to discontinue treatment, this should be carried out gradually, over a period of at least eight weeks, in order to minimise the risk of rebound anxiety. ${ }^{46}$ It has been found that supplemental CBT, offered at the time of treatment withdrawal, has lowered relapse rates in some people. ${ }^{66,67}$

In the long term, most treatment guidelines advocate a collaborative approach between patient and healthcare provider to optimise management. As this chronic disease often features intermittent relapse-remission cycles, the general practitioner should strive to empower individuals to take responsibility for the day-to-day management of their condition. Thus, persons with PD should be encouraged to take a proactive role in adhering to prescribed treatments, adopting improved lifestyle habits and coping strategies and monitoring their responses to therapeutic interventions. ${ }^{3}$ Self-rating symptom scales may be useful in this regard. For example, the Panic and Agoraphobia Scale ${ }^{68}$ and the Panic Disorder Severity Scale ${ }^{69}$ may be used by individuals to monitor their own symptom severity, functional impairment and treatment response.

\section{Treatment of non-responders}

The primary level approach to the individual who does not respond adequately to first-line treatment should begin with a critical evaluation of the initial diagnosis of PD, the presence of co-morbidities that may have been overlooked, whether or not he or she is adherent to the prescribed treatment (paying particular attention to troublesome sideeffects $)^{70}$ and whether or not a therapeutic trial of appropriate dose and duration has been undertaken.

Once a case of treatment non-response has been established (defined as a failure to achieve at least $50 \%$ symptom reduction, as measured by a standard rating scale after a minimum of six weeks of treatment at a suitable 
dosage), ${ }^{71}$ consideration should be given to switching to a different first-line agent. As there is no clear evidence to support dose escalation in treatment of non-responders, ${ }^{45} \mathrm{a}$ switch strategy should be the next step at the primary level.

However, should this also prove to be unsuccessful, the general practitioner should consider referring the patient to a specialist psychiatrist for the initiation of second-line therapy. Suitable second-line agents include the tricyclic antidepressants, e.g. clomipramine and imipramine, ${ }^{72}$ and benzodiazepines, e.g. alprazolam and clonazepam. ${ }^{73,74}$

Augmentation strategies may also be helpful in treating non-responders. Third-line agents which may be suitable as adjuncts include atypical antipsychotics. e.g. olanzapine. ${ }^{75}$ However, as the tolerability and potential drug interactions of these agents are more problematic than the SSRIs, referral to more specialised psychiatric care is warranted. Some guidelines also suggest the use of adjunctive CBT in individuals who have failed to respond adequately to pharmacotherapy. ${ }^{45,46}$ Group CBT, in particular, has been found to be effective in some cases. ${ }^{76,77}$

\section{When to refer to psychiatric services}

As discussed, the general practitioner should consider referral of those who have failed to respond to first-line treatment. Additional high-risk subgroups that warrant specialised psychiatric evaluation include children and adolescents, the elderly, pregnant women and highly comorbid individuals, particularly those with severe major depression or active suicidality. ${ }^{45}$

\section{Special populations}

\section{Children and adolescents}

While initially conceptualised as a disorder that occurs exclusively in adulthood, it is now recognised that a significant proportion of adults with PD report the onset of symptoms before the age of $18 .^{78} \mathrm{PD}$ in childhood and adolescence is often disabling and may be associated with a range of psychological, social and school-related impairments. ${ }^{79}$ Risk factors include cognitive-affective sensitivity, e.g. negative affectivity; ${ }^{80}$ environmental stress, e.g. family conflict; ${ }^{81}$ and heritable factors, e.g. a family history of PD. ${ }^{82,83}$ While the clinical presentation is similar to that of adults with the disorder, paediatric presentations are often complicated by an exceptionally high rate of co-morbidity with other anxiety disorders or major depression. ${ }^{84,85} \mathrm{As}$ is the case in adults, SSRIs appear to be the mainstay of pharmacotherapy in paediatric cases. ${ }^{45}$ However, empirical evidence for this is sparse, and arguably, nonpharmacological interventions should be the first-line option in children and adolescents. Generally, ageappropriate psycho-education of the individual and his or her family and psychological therapy should be employed by a specialist healthcare provider. ${ }^{45,46}$

\section{The elderly}

Although agoraphobia in the elderly may be relatively common, ${ }^{86}$ PD in persons over the age of 65 is not. ${ }^{1}$ Nonetheless, the general practitioner should be prepared to manage the complexities of such cases. Deteriorating physical, cognitive and psychological functioning may worsen prognosis and impair treatment response. Furthermore, high rates of co-morbid medical disorders and polypharmacy may complicate treatment. As there is a paucity of evidence for the management of PD in the elderly, most guidelines suggest following the recommendations that are provided for younger adults, while remaining cognisant of these particular challenges.

\section{Conclusion}

PD is a common disorder that often presents in medical settings and that may lead to high healthcare utilisation. In South Africa, the general practitioner is ideally placed to identify individuals with this disorder, to implement appropriate interventions and to refer to more specialised psychiatric services when necessary. Fortunately, in most cases, persons with panic disorder respond to firstline, easy-to-use interventions, many of which may be implemented in general practice.

\section{References}

1. Herman AA, Stein DJ, Seedat S, et al. The South African Stress and Health (SASH) study: 12-month and lifetime prevalence of common mental disorders. S Afr Med J. 2009:99(5 Pt 2):339-344.

2. Kessler RC, Chiu WT, Demler O, Walters EE. Prevalence, severity, and comorbidity of 12-month DSM-IV disorders in the National Comorbidity Survey Replication. Arch Gen Psychiatry. 2005;62(6):617-627.

3. Roy-Byrne R, Wagner A, Schraufnagel T. Understanding and treating panic disorder in the primary care setting. J Clin Psychiatry. 2005;66 (Supp 4):16-22.

4. Frances A. DSM-IV, Diagnostic and Statistical Manual of Mental Disorders. 4th ed. Washington DC: American Psychiatric Association; 1994.

5. American Psychiatric Association. Diagnostic and Statistical Manual of Mental Disorders. 4th ed. Washington, USA: American Psychiatric Press; 2000.

6. E01 Panic disorder. American Psychiatric Association [homepage on the Internet]. 2012. c2012. Available from: http://www.dsm5.org/ProposedRevision/ Pages/proposedrevision. aspx?rid $=409$

7. Nutt $\mathrm{D}$, Ballenger $\mathrm{J}$, editors. Anxiety disorders: panic disorder and social anxiety disorder. Massachusetts: Blackwell Publishing; 2005.

8. Hettema JM, Neale MC, Kendler KS. A review and meta-analysis of the genetic epidemiology of anxiety disorders. Am J Psychiatry. 2001;158(10):1568-1578.

9. Weissman MM, Wickramaratne P, Adams PB, et al. The relationship between panic disorder and major depression: a new family study. Arch Gen Psychiatry. 1993;50(10):767-780.

10. Goldstein RB, Weissman MM, Adams PB, et al. Psychiatric disorders in relatives of probands with panic disorder and/or major depression. Arch Gen Psychiatry. 1994;51(5):383-394.

11. Finn CT, Smoller JW. The genetics of panic disorder. Curr Psychiatry Rep. 2001;3(2):131-137

12. Kendler KS, Neale MC, Kessler RC, et al. Panic disorder in women: a populationbased twin study. Psychol Med. 1993;23(2):397-406. 
13. Perna G, Caldirola D, Arancio C, Bellodi L. Panic attacks: a twin study. Psychiatry Res. 1997;66(1):69-71.

14. Gorman JM, Kent JM, Sullivan GM, Coplan JD. Neuroanatomical hypothesis of panic disorder, revised. Am J Psychiatry. 2000;157(4):493-505.

15. Tweed JL, Schoenbach VJ, George LK, Blazer DG. The effects of childhood parental death and divorce on six-month history of anxiety disorders. $\mathrm{Br} \mathrm{J}$ Psychiatry. 1989;154:823-828.

16. Faravelli C, Pallanti S. Recent life events and panic disorder. Am J Psychiatry. 1989;146(5):622-626.

17. Horesh N, Amir M, Kedem P, et al. Life events in childhood, adolescence and adulthood and the relationship to panic disorder. Acta Psychiatr Scand. 1997; 96(5):373-378.

18. Gorman J, Liebowitz M, Fyer A, Stein J. A neuroanatomical hypothesis for panic disorder. Am J Psychiatry. 1989;146(2):148-161.

19. Dantendorfer K, Prayer D, Kramer J, et al. High frequency EEG and MRI brain abnormalities in panic disorder. Psychiatry Res. 1996;68(1):41-53.

20. Vythilingam M, Anderson ER, Goddard A, et al. Temporal lobe volume in panic disorder: a quantitative magnetic resonance imaging study. Psychiatry Res. 2000;99(2):75-82.

21. Maron E, Shlik J. Serotonin function in panic disorder: important, but why? Neuropsychopharmacology. 2006;31(1):1-11.

22. Alvarenga ME, Richards JC, Lambert G, Esler MD. Psychophysiological mechanisms in panic disorder: a correlative analysis of noradrenaline spillover, neuronal noradrenaline reuptake, power spectral analysis of heart rate variability, and psychological variables. Psychosom Med. 2006;68(1): 8-16.

23. Kennedy JL, Bradwejn J, Koszycki D, et al. Investigation of cholecystokinin system genes in panic disorder. Mol Psychiatry. 1999;4(3):284-285.

24. Lydiard RB, Ballenger JC, Laraia MT, et al. CSF cholecystokinin concentrations in patients with panic disorder and in normal comparison subjects. Am J Psychiatry. 1992;149(5):691-693

25. Deckert J, Catalano M, Syagailo $\mathrm{YV}$, et al. Excess of high activity monoamine oxidase A gene promoter alleles in female patients with panic disorder. Hum Mo Genet.1999;8(4):621-624.

26. Woo JM, Yoon KS, Yu BH. Catechol O-methyltransferase genetic polymorphism in panic disorder. Am J Psychiatry. 2002;159(10):1785-1787.

27. Jacob C, Domschke K, Gajewska A, et al. Genetics of panic disorder: focus on association studies and therapeutic perspectives. Expert Rev Neurother. 2010;10(8):1273-1284.

28. Na HR, Kang EH, Lee JH, Yu BH. The genetic basis of panic disorder. J Korean Med Sci. 2011;26(6):701-710.

29. Fyer AJ, Hamilton SP, Durner M, Haghighi F, et al. A third-pass genome scan in panic disorder: evidence for multiple susceptibility loci. Biol Psychiatry. 2006;60(4):388-401

30. Otowa T, Yoshida E, Sugaya N, et al. Genome-wide association study of panic disorder in the Japanese population. J Hum Genet. 2009;54(2):122-126.

31. Otowa $\mathrm{T}$, Tanii $\mathrm{H}$, Sugaya $\mathrm{N}$, et al. Replication of a genome-wide association study of panic disorder in a Japanese population. J Hum Genet. 2010;55(2):91-96.

32. Williams DR, Herman A, Stein DJ, et al. Twelve-month mental disorders in South Africa: prevalence, service use and demographic correlates in the populationbased South African Stress and Health Study. Psychol Med. 2008; 38(2):211-220.

33. Panic attack. American Psychiatric Association [homepage on the Internet] 2012. c2102. Available from: http://www.dsm5.org/ProposedRevision/Pages/ proposedrevision. aspx?rid=404\#

34. Kircanski K, Craske MG, Epstein AM, Wittchen HU. Subtypes of panic attacks: a critical review of the empirical literature. Depress Anxiety. 2009;26(10):878-887.

35. Katon W. Panic disorder: epidemiology, diagnosis, and treatment in primary care. J Clin Psychiatry. 1986;47(Suppl):21-30.

36. Klein D. False suffocation alarms, spontaneous panics and related conditions: an integrative hypothesis. Arch Gen Psychiaty. 1993;50(4):306-317.

37. Zandbergen J, Bright $\mathrm{M}$, Pols $\mathrm{H}$, et al. Higher lifetime prevalence of respiratory diseases in panic disorder. Am J Psychiatry. 1991;148(11):1583-1585.

38. Perna G, Bertani A, Politi E, et al. Asthma and panic attacks. Biol Psychiatry.
$1997: 42(7): 625-630$.

39. Carr RE. Panic disorder and asthma. J Asthma. 1999;36(2):143-152

40. Livermore N, Sharpe L, McKenzie D. Panic attacks and panic disorder in chronic obstructive pulmonary disease: a cognitive behavioral perspective. Respir Med. 2010;104(9):1246-1253.

41. Agoraphobia. American Psychiatric Association [homepage on the Internet]. 2012. c2012. Available from: http://www.dsm5.org/ProposedRevision/Pages/ proposedrevision . aspx? rid $=405$

42. Pilowsky DJ, Olfson M, Gameroff MJ, et al. Panic disorder and suicidal ideation in primary care. Depress Anxiety. 2006;23(1):11-16

43. Katon W. Panic disorder: relationship to high medical utilization, unexplained physical symptoms, and medical costs. J Clin Psychiatry. 1996;57(Suppl 10):11-18.

44. Zaubler TS, Katon W. Panic disorder in the general medical setting. J Psychosom Res. 1998;44(1):25-42.

45. Baldwin SA, Anderson IM, Nutt DJ, et al. Evidence-based guidelines for the pharmacological treatment of anxiety disorders: recommendations from the British Association for Psychopharmacology. J Pharmacol. 2005;19(6):567-596.

46. Swinson RP, Antony MM, Bleau PB, et al. Clinical practice guidelines: management of anxiety disorders. Can J Psychiatry. 2006;51(8 Suppl 2):1-92.

47. Bandelow B, Zohar J, Hollander E, et al. World Federation of Societies of Biological Psychiatry (WFSBP) guidelines for the pharmacological treatment of anxiety, obsessive-compulsive and posttraumatic stress disorders: first revision. World J Biol Psychiatry. 2008;9(4):248-312.

48. Michelson D, Lydiard RB, Pollack MH, et al. Outcome assessment and clinica improvement in panic disorder: evidence from a randomized controlled tria of fluoxetine and placebo. The Fluoxetine Panic Disorder Study Group. Am J Psychiatry. 1998;155(11):1570-1577

49. Michelson D, Allgulander C, Dantendorfer K, et al. Efficacy of usual antidepressan dosing regimens of fluoxetine in panic disorder: randomised, placebo-controlled trial. Br J Psychiatry. 2001;179:514-518.

50. Londborg PD, Wolkow R, Smith WT, et al. Sertraline in the treatment of panic disorder. A multi-site, double-blind, placebo-controlled, fixed-dose investigation. Br J Psychiatry. 1998;173:54-60.

51. Pollack MH, Otto MW, Worthington JJ, et al. Sertraline in the treatment of panic disorder: a flexible-dose multicenter trial. Arch Gen Psychiatry. 1998;55(11):1010-1016

52. Ballenger JC, Wheadon DE, Steiner M, et al. Double-blind, fixed-dose, placebocontrolled study of paroxetine in the treatment of panic disorder. Am J Psychiatry. 1998;155(1):36-42

53. Pollack MH, Worthington JJ, Otto MW, et al. Venlafaxine for panic disorder: results from a double-blind, placebo-controlled study. Psychopharmacol Bull. 1996;32(4):667-670.

54. Bradwejn J, Ahokas A, Stein DJ, et al. Venlafaxine extended-release capsules in panic disorder: flexible-dose, double-blind, placebo-controlled study. $\mathrm{Br} \mathrm{J}$ Psychiatry. 2005;187:352-359.

55. Stein MB, Goin MK, Pollack MH. Practice guidelines for the treatment of patients with panic disorder. $2^{\text {nd }}$ ed. Washington (DC): American Psychiatric Association Work Group on Panic Disorder; 2010.

56. Roy-Byrne P, Wingerson D, Cowley D, Dager S. Psychopharmacologic treatment of panic, generalized anxiety disorder, and social phobia. Psychiatr Clin North Am. 1993;16(4):719-735.

57. Asnis G, Hameedi F, Goddard A, et al. Fluvoxamine in the treatment of panic disorder: a multi-center, double-blind, placebo-controlled study in outpatients. Psychiatry Res. 2001;103(1):1-14

58. Pollack MH, Simon NM, Worthington JJ, et al. Combined paroxetine and clonazepam treatment strategies compared to paroxetine monotherapy for panic disorder. J Psychopharmacol. 2003;17(3):276-282

59. Goddard AW, Brouette T, Almai A, et al. Early coadministration of clonazepam with sertraline for panic disorder. Arch Gen Psychiatry. 2001;58(7):681-686.

60. Kasper S, Resinger E. Panic disorder: the place of benzodiazepines and selective serotonin reuptake inhibitors. Eur Neuropsychopharmacol. 2001;11(4):307-321.

61. Chouinard G. Issues in the clinical use of benzodiazepines: potency, withdrawal, 
and rebound. J Clin Psychiatry. 2004;65(Suppl 5):7-12.

62. Clum GA, Surls R. A meta-analysis of treatments for panic disorder. J Consult Clin Psychol. 1993;61(2):317-326.

63. Gould R, Otto M, Pollack M. A meta-analysis of treatment outcome for panic disorder. Clin Psychol Psychother. 1995;15:819-844.

64. Landon TM, Barlow DH. Cognitive-behavioral treatment for panic disorder: current status. J Psychiatr Pract. 2004;10(4):211-226

65. Rickels K, Schweizer E. Panic disorder: long-term pharmacotherapy and discontinuation. J Clin Psychopharmacol. 1998;18(6 Suppl 2):12S-18S.

66. Otto MW, Deveney C. Cognitive-behavioral therapy and the treatment of panic disorder: efficacy and strategies. J Clin Psychiatry. 2005;66 Suppl 4:28-32.

67. Schmidt NB, Wollaway-Bickel K, Trakowski JH, et al. Antidepressant discontinuation in the context of cognitive behavioral treatment for panic disorder. Behav Res Ther. 2002;40(1):67-73

68. Bandelow B. Assessing the efficacy of treatments for panic disorder and agoraphobia. II. The Panic and Agoraphobia Scale. Int Clin Psychopharmacol. 1995;10(2):73-81.

69. Shear M, Brown T, Barlow D, et al. Multicenter collaborative panic disorder severity scale. Am J Psychiatry. 1997;154(11):1571-1575.

70. Cowley DS, Ha EH, Roy-Byrne PP. Determinants of pharmacologic treatment failure in panic disorder. J Clin Psychiatry. 1997;58(12):555-561.

71. Bandelow B, Rüther E. Treatment-resistant panic disorder. CNS Spectr. 2004:9(10):725-739.

72. Bakker A, van Balkom A, Spinhoven P. SSRIs vs. TCAs in the treatment of panic disorder: a meta-analysis. Acta Psychiatr Scand. 2002;106(3):163-167.

73. Tesar GE, Rosenbaum JF, Pollack MH, et al. Double-blind, placebo-controlled comparison of clonazepam and alprazolam for panic disorder. J Clin Psychiatry. 1991;52(2):69-76.

74. Pollack MH, Otto MW, Tesar GE, et al. Long-term outcome after acute treatment with alprazolam or clonazepam for panic disorder. J Clin Psychopharmacol. 1993;13(4):257-263.
75. Sepede G, De Berardis D, Gambi F, et al. Olanzapine augmentation in treatmentresistant panic disorder: a 12-week, fixed-dose, open-label trial. J Clin Psychopharmacol. 2006;26(1):45-49.

76. Otto MW, Pollack MH, Penava SJ, Zucker BG. Group cognitive behaviour therapy for patients failing to respond to pharmacotherapy for panic disorder: a clinical case series. Behav Res Ther. 1999;37(8): 763-770.

77. Heldt E, Manfro GG, Kipper L, et al. Treating medication-resistant panic disorder: predictors and outcome of cognitive-behavior therapy in a Brazilian public hospital. Psychother Psychosom. 2003;72(1):43-48.

78. Masi G. Favilla L, Romano R. Panic disorder in children and adolescents. Panminerva Med. 1999;41(2):153-156

79. Diler RS. Panic disorder in children and adolescents. Yonsei Med J. 2003:44(1):174-179.

80. Mattis SG, Ollendick TH. Children's cognitive responses to the somatic symptoms of panic. J Abnorm Child Psychol. 1997;25(1):47-57.

81. Macaulay JL, Kleinknecht RA. Panic and panic attacks in adolescents. J Anxiety Disorders. 1989;3(4):221-241.

82. Biederman J, Faraone SV, Marrs A, et al. Panic disorder and agoraphobia in consecutively referred children and adolescents. J Am Acad Child Adolesc Psychiatry. 1997;36(2):214-223.

83. Kearney CA, Albano AM, Eisen AR, et al. The phenomenology of panic disorde in youngsters: an empirical study of a clinical sample. J Anxiety Disord. 1997:11(1):49-62.

84. Alessi NE, Magen J. Panic disorders in psychiatrically hospitalized children. Am J Psychiatry. 1988;145(11):1450-1452.

85. Alessi NE, Robbins DR, Dilsaver SC. Panic and depressive disorders among psychiatrically hospitalized adolescents: A review. Psychiatry Res. 1987:20(4):275-283.

86. McCabe L, Cairney J, Veldhuizen S, et al. Prevalence and correlates of agoraphobia in older adults. Am J Geriatr Psychiatry. 2006;14(6):515-522.

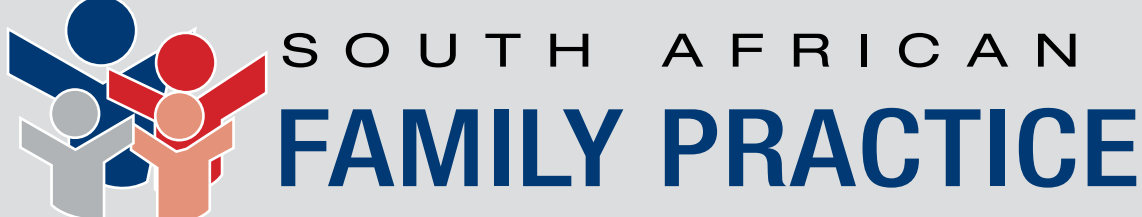

\section{ETHICS CPD SUPPLEMENT AND FREE ONLINE CPD}

\section{Dear SAFP Readers,}

Please note that the Ethics CPD Supplement has now moved to the JanFeb 2013 edition to extend its validity to 12 months, rather than 3 months.

You will be able to submit your answers up to the middle of March 2013 to obtain your ethics CPD points.

We apologise for any inconvenience.

Visit us at www.medpharm.co.za to register for FREE ONLINE CPD.

Phone our CPD Helpline at 0722336603 for assistance.

Regards

Publisher 